\title{
5-7-5 line defects on As/Si(100): A general stress-relief mechanism for V/IV surfaces
}

\author{
W. E. McMahon, ${ }^{1}$ Iskander G. Batyrev, ${ }^{1,2}$ T. Hannappel,,${ }^{1,3}$ J. M. Olson, ${ }^{1}$ and S. B. Zhang ${ }^{1}$ \\ ${ }^{1}$ National Renewable Energy Laboratory, Golden, Colorado 80401, USA \\ ${ }^{2}$ Department of Physics and Astronomy, Vanderbilt University, Nashville, Tennessee 37235, USA \\ ${ }^{3}$ Hahn-Meitner Institute, Solar Energy (SE-4), Glienicker Stresse 100, Berlin D-14109, Germany
}

(Received 24 April 2006; published 6 July 2006)

\begin{abstract}
An entire family of nano-scale trenches, ridges, and steps has been observed experimentally on $\mathrm{AsH}_{3}$-exposed $\mathrm{Si}(100)$. Some of these line structures have been observed previously, but their structures have remained a mystery. Theoretical modeling shows that they are all based upon the same stress-relieving 5-7-5 core structure. The strong similarities between line structures on As/Si(100), P/Si(100), As/Ge(100), and other V/IV surfaces lead to a much broader conclusion: 5-7-5 line structures are a general form of stress relief for group-V terminated $\mathrm{Si}$ and Ge surfaces.
\end{abstract}

DOI: 10.1103/PhysRevB.74.033304

Crystal surfaces are, in general, elastically stressed, so the lattice constant of the underlying crystal is rarely ideal. Because surface stress plays such an important role in the epitaxial growth of materials, ${ }^{1}$ it has been the subject of much study. ${ }^{2-5}$ Group-V terminated $\mathrm{Si}$ and Ge surfaces are nearly ideal for studies of surface stress. ${ }^{3,4,6}$ Group-V atoms chemically passivate $\mathrm{Si}$ and Ge surfaces, ${ }^{7,8}$ so any reorganization of the surface is primarily a response to surface stress.

Recently, a line structure with two 5-atom rings bracketing a central 7-atom ring was found to relieve stress on the As/Ge(100) surface. ${ }^{9}$ It is now becoming apparent that "5$7-5$ " line structures relieve stress on many different group- $\mathrm{V}$ terminated $\mathrm{Si}$ and $\mathrm{Ge}$ surfaces. Variations have been found on $\mathrm{As} / \mathrm{Ge}(111),{ }^{10} \mathrm{Bi} / \mathrm{Si}(100),{ }^{11}$ and $\mathrm{Sb} / \mathrm{Si}(100)$ (Ref. 12) surfaces. In hindsight, scanning tunneling microscope (STM) images of $\mathrm{P} / \mathrm{Si}(111),{ }^{13} \mathrm{P} / \mathrm{Si}(100),{ }^{14}$ and $\mathrm{As} / \mathrm{Si}(100)$ (Ref. 15) also seem to contain 5-7-5 structures. These structures are all extremely straight and can also be very long, and can therefore serve as templates for quantum wires. ${ }^{16}$ Here we will focus primarily on the $\mathrm{As} / \mathrm{Si}(100)$ surface, then broaden the scope to include $\mathrm{P} / \mathrm{Si}(100)$ and other V/IV surfaces.

Given the attention that $\mathrm{As} / \mathrm{Si}(100)$ surfaces have received as a possible substrate for GaAs epitaxy, ${ }^{7,15,17-22}$ it is remarkable that these structures are just now being modeled. This is partly because most STM studies of $\mathrm{As} / \mathrm{Si}(100)$ were done under conditions unfavorable for line defect formation. Line defects appeared only as incidental structures, and received only a passing mention. To our knowledge, only one study has specifically focused on $\mathrm{As} / \mathrm{Si}(100)$ line defects. ${ }^{15}$ It carefully considered their strain-driven nature, but could only speculate as to what their structure might be. No modeling was ever done, because no model existing at the time fit with experimental observations.

Here we will present work done under conditions very favorable for line defect formation, and the resulting surfaces are littered with stress-relieving trenches, ridges, and reconstructed steps. Theoretical modeling shows that the entire family of line structures is based upon a single 5-7-5 core structure. The relationship between sample preparation conditions and 5-7-5 line structure formation will be discussed.

In this study, both singular and vicinal $\mathrm{Si}(100)$ substrates were prepared by first cleaning in a solution of concentrated aqueous ammonia: $\mathrm{H}_{2} \mathrm{O}_{2}\left(30 \%\right.$ in $\left.\mathrm{H}_{2} \mathrm{O}\right): \mathrm{H}_{2} \mathrm{O}(2: 1: 10)$ at room temperature for $5 \mathrm{~min}$, then rinsing in $\mathrm{H}_{2} \mathrm{O}$ for $1 \mathrm{~min}$, followed by a dilute $\mathrm{HF}$ dip $\left(10 \%\right.$ in $\left.\mathrm{H}_{2} \mathrm{O}\right)$ for $30 \mathrm{sec}$. They were then loaded into a metalorganic chemical-vapordeposition (MOCVD) reactor operated with an $\mathrm{H}_{2}$ carrier gas flow of $6 \mathrm{~L} / \mathrm{min}$ at 50 torr. All experiments began with an anneal at $825{ }^{\circ} \mathrm{C}$ under 40 mtorr $\mathrm{AsH}_{3}$ (diluted in 50 torr $\mathrm{H}_{2}$ ) to remove surface oxides and contaminants. ${ }^{23}$ Samples were then annealed at 650 to $825^{\circ} \mathrm{C}$ under an $\mathrm{AsH}_{3}$ partial pressure of 17 to 830 mtorr, or under $\mathrm{H}_{2}$ only (without $\mathrm{AsH}_{3}$ ), in which case an ever-present background partial pressure of $\mathrm{As}_{x}\left(\mathrm{As}_{2}\right.$ and/or $\left.\mathrm{As}_{4}\right)$ becomes significant. After annealing, the samples were passively cooled to room temperature in approximately 2 or $3 \mathrm{~min}$. If $\mathrm{AsH}_{3}$ was used during the anneal, an $\mathrm{AsH}_{3}$ flow was also maintained during sample cooling.

After preparation in the MOCVD chamber, samples were transferred under vacuum to an ultrahigh vacuum (UHV) chamber for study with low-energy electron diffraction (LEED), Auger electron spectroscopy (AES), and STM. All surfaces were studied as cooled, with no additional surface preparation after leaving the MOCVD chamber. Carbon and oxygen peaks in post-anneal Auger electron spectra were negligible or absent, indicating very clean surfaces.

$\mathrm{Si}(100)$ surfaces annealed under $\mathrm{AsH}_{3}$ (Fig. 1) contain a wealth of structures. Most obvious are the many shallow rectangular craters caused by $\mathrm{AsH}_{3}$ etching. Quite often, preferential etching of terraces converts a step (dashed arrow) into a ridge (solid arrow). Nothing like this was seen in earlier studies using $\mathrm{As}_{x}$ under vacuum, ${ }^{7,15,18,19,22}$ nor do we see evidence of etching for samples annealed under background $\mathrm{As}_{x}$ in an $\mathrm{H}_{2}$ ambient. Our $\mathrm{As}_{x}$-annealed surfaces simply consist of flat dimerized terraces separated by (mostly bulklike) 3-ML type- $B$ and 1-ML type- $A$ steps. ${ }^{21,22}$ (1 ML $=1.358 \AA$, and the $A / B$ step notation is Chadi's. ${ }^{24}$ ) We therefore conclude that $\mathrm{AsH}_{3}$ etches $\mathrm{Si}$ surfaces, whereas $\mathrm{As}_{x}$ and $\mathrm{H}_{2}$ do not. The most reasonable explanation is that $\mathrm{AsH}_{3}$ decomposition at the surface releases atomic $\mathrm{H}$, which converts $\mathrm{Si}(s)$ into $\mathrm{SiH}_{4}(v)$. Atomic $\mathrm{H}$ released by $\mathrm{AsH}_{3}$ decomposition also explains why the $\mathrm{Si}$ deoxidization temperature can be lowered to $850^{\circ} \mathrm{C}$ in an $\mathrm{AsH}_{3}$ flux. ${ }^{23}$

In addition to the shallow etched craters, Fig. 1 contains a whole family of line structures. A few of these ridges, trenches, and reconstructed steps have been labeled with let- 


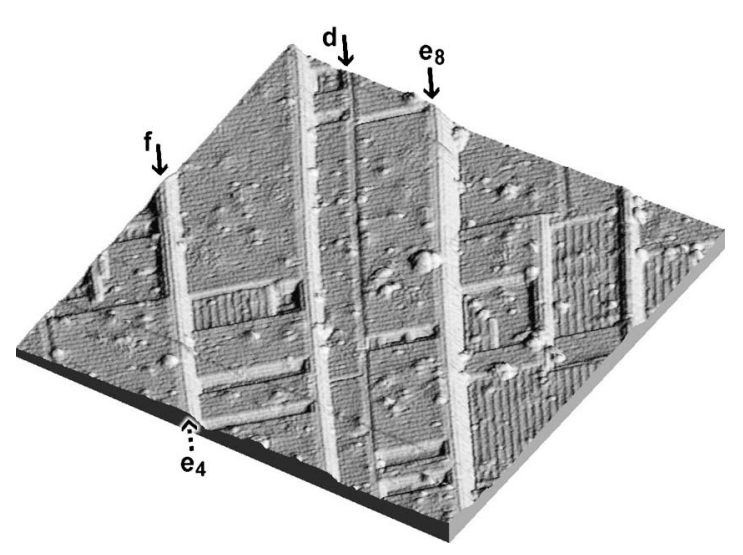

FIG. 1. A vicinal As/Si(100) surface miscut $2^{\circ}$ toward (111), annealed under $42 \mathrm{mtorr} \mathrm{AsH}_{3}$ for $10 \mathrm{~min}$ at $725^{\circ} \mathrm{C}$. The letters correspond to the 5-7-5 structures in Fig. 2. This $800 \AA \times 800 \AA$ STM image is artificially illuminated from the right. $V_{\text {sample }}=$ $-2.5 \mathrm{~V}, I_{\text {tun }}=0.04 \mathrm{nA}$.

ters corresponding to the 5-7-5 structures in Fig. 2. Structure " $d$ " is particularly interesting, as it stands out very conspicuously from the surrounding terrace and cannot be mistaken for a dimer vacancy line. Compared with a dimer vacancy line, ${ }^{25}$ structure " $d$ " is (1) too straight, (2) too shallow $(0.5 \pm 0.1 \mathrm{ML})$ and $(3)$ too wide (replacing two dimers instead of just one).

Figure 2 shows schematically how a single 5-7-5 core structure can be used to construct the entire family of observed line structures. A 5-7-5 structure forms when the two $\mathrm{Si}$ atoms circled in structure " $a$ " shift to the positions circled in structure " $b$." The resulting 5-7-5 structure (shaded gray) consists of two 5-atom rings bracketing a central 7-atom ring. The two circled $\mathrm{Si}$ atoms now sit horizontally side by side, laterally compressing the surrounding lattice. Because the As-As dimers on the surrounding terrace would prefer to sit on a smaller lattice, ${ }^{4,6}$ this arrangement reduces the average surface stress.

To distinguish between a 5-7-5 structure and a bulklike structure, it is useful to identify the ways in which sites " $A$ " and " $B$ " differ from sites " 1 " and " 2 ." Three main differences are: (1) The height of sites 1 and 2 is offset from adjacent terraces by approximately $(m+1 / 2)$ ML, where $m$ is an integer. Examples of this height difference are shown by dashed lines in Fig. 2. The same offset for sites $A$ and $B$ is $m$ ML. (2) Sites $A$ and $B$ dimerize parallel to the line structure [perpendicular to the page in Fig. 2(a)]. Sites 1 and 2 do not. (3) Because a 5-7-5 line is heavily rebonded and difficult to kink, sites 1 and 2 will lie along straight, unkinked lines. In contrast, a simple bulklike structure such as a vacancy line ${ }^{25}$ will tend to wander.

To illustrate these characteristics, some representative line structures are shown in Fig. 3. In the main image, the line structure between the arrows contains two sites which sit midway in height between terraces " 0 " and " 1 ". No dimerization of these sites parallel to the axis of the structure is visible. The line structure remains straight and level as it passes through an entire family of structures ("c"-" $f$ ") formed by $\mathrm{AsH}_{3}$-etching of the adjacent terraces. A 5-7-5 line structure is consistent with these observations. A bulklike structure is not.

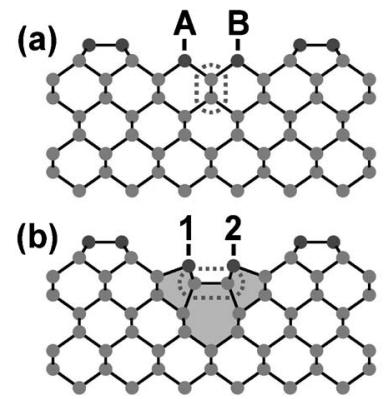

(c)

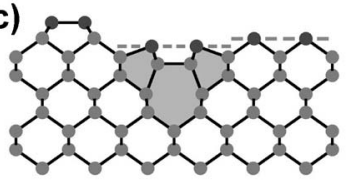

(d)

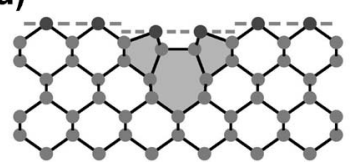

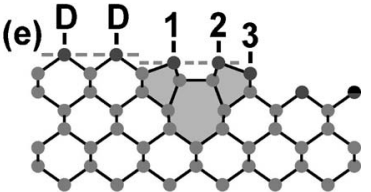

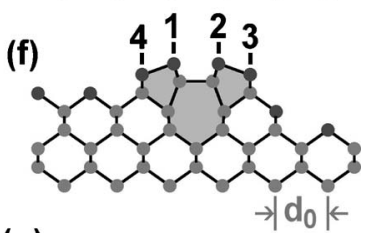

(g)

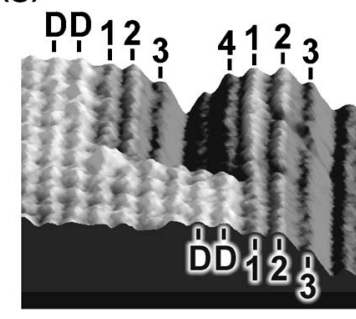

FIG. 2. (a) Bulklike type- $A$ trench, (b) 5-7-5 type- $A$ trench, (c) 5-7-5 1-ML type- $A$ step, (d) 5-7-5 type- $B$ trench, (e) 5-7-5 type- $B$ step, and (f) 5-7-5 ridge. Elsewhere in this paper these are called structures " $a$ "- $f$ ", and $e_{h}$ indicates a variation of structure $e$ in which the lower terrace height is adjusted to give a step height of $h$ ML. As-As dimer bonds on the left-side terrace are either perpendicular (type $A$ ) or parallel (type $B$ ) to the line structure. All surface atoms are triply-bonded As (dark gray). All sub-surface atoms are quadruply-bonded Si (light gray). (g) STM image, artificially illuminated from the right. Continuity of a 5-7-5 core structure is seen where $\mathrm{AsH}_{3}$-etching of the upper terrace has converted part of a type- $B$ step into a ridge. To better show height differences, the ratio of height to width has been increased by $72 \%$. $V_{\text {sample }}=-2.5 \mathrm{~V}$, $I_{\text {tun }}=0.04 \mathrm{nA}$.

An example of structure $b$ is shown in the inset of Fig. 3 . It becomes structure $c$ when $1 \mathrm{ML}$ of upper-terrace atoms is removed. A single core structure (dashed arrows) passes through both, 1/2 ML in height below the lower terrace. A trench at the base of a $1 A$ step (structure $c$ ) was also clearly imaged by Jackson et al., ${ }^{15}$ and is particularly difficult to explain without a 5-7-5 structure. Interestingly, a very similar step structure is seen for $\mathrm{PH}_{3}$-exposed $\mathrm{P} / \mathrm{Si}(100)$. In fact, all of the topographic characteristics just discussed apply equally well to $\mathrm{P} / \mathrm{Si}(100)$ line structures, ${ }^{14,26}$ suggesting that they are also 5-7-5 structures.

To demonstrate the energetic stability of 5-7-5 structures, structures $a, b, d$, and $e$ of Fig. 2 were modeled theoretically. Calculations were done using the plane-wave pseudopotential method (VASP 4.6) with projector-augmented waves. Supercells with 120 to 260 atoms in an 8- to 9-layer thick slab geometry were separated by 6 to 7 layers of vacuum to prevent the interaction of the top surface with hydrogenated back surface. Rectangular supercells were used for trenches, and skewed supercells were used for steps. The structures were relaxed using the conjugate gradient method with selective dynamics until forces were less than $0.05 \mathrm{eV} / \AA$. The calculations used 2 irreducible $k$ points and a cutoff energy of $150 \mathrm{eV}$. 


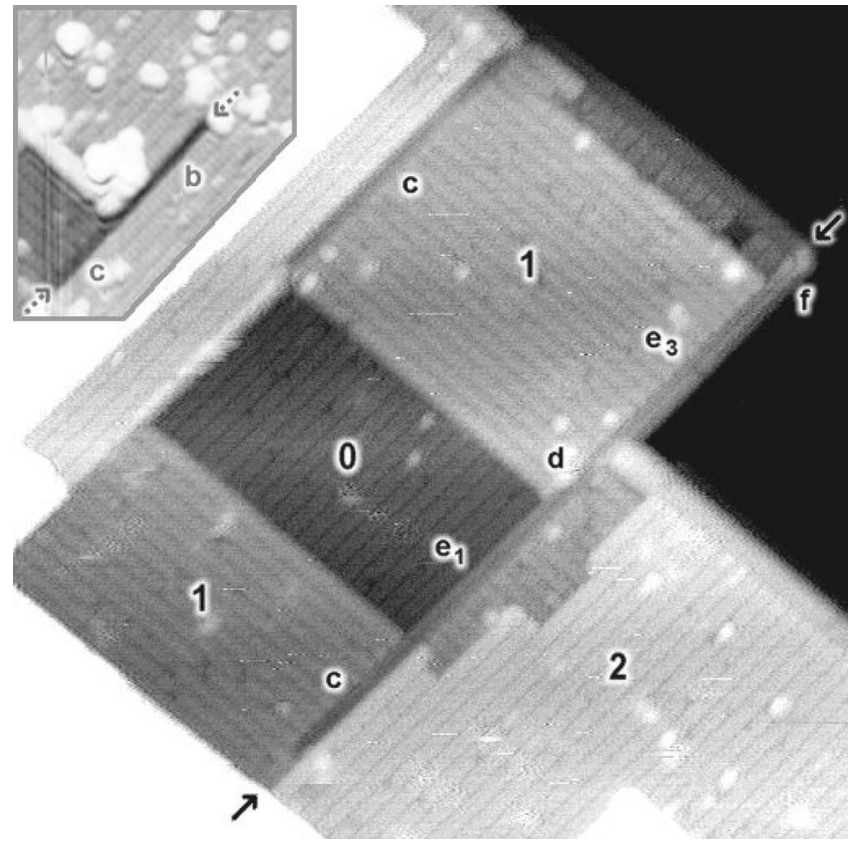

FIG. 3. (Main image) A $400 \AA \times 400 \AA$ STM image of As/Si(100) miscut $2^{\circ}$ toward (111) annealed under 42 mtorr $\mathrm{AsH}_{3}$ for $10 \mathrm{~min}$ at $805{ }^{\circ} \mathrm{C}$. The grayscale has been expanded to span only 3 monolayers (terraces 0,1 and 2). $V_{\text {sample }}=-2.5 \mathrm{~V}, I_{\text {tun }}$ $=0.07 \mathrm{nA}$. (Inset) A $175 \AA \times 200 \AA$ STM image of $\mathrm{As} / \mathrm{Si}(100)$. This surface was annealed under $42 \mathrm{mtorr} \mathrm{AsH}_{3}$ for $5 \mathrm{~min}$ at $725^{\circ} \mathrm{C}$. $V_{\text {sample }}=-3.0 \mathrm{~V}, I_{\text {tun }}=0.07 \mathrm{nA}$. In both images, the letters correspond to the 5-7-5 line structures of Fig. 2.

We begin with structures $a$ and $b$. For a trench spacing of $46.1 \AA\left(12 d_{0}\right)$, the 5-7-5 structure is $565 \mathrm{meV}$ lower in energy than the flat surface, per unit trench length $d_{0}\left(d_{0}\right.$ $=3.84 \AA$ ). A bulklike trench [Fig. 2(a)] offers less surface stress relief than a 5-7-5 trench, and is only $357 \mathrm{meV}$ per unit trench length $\left(d_{0}\right)$ lower in energy than a flat surface. These surfaces contain no dangling bonds, ${ }^{7,8}$ so these energy differences are primarily due to surface stress reduction.

The transformation between a bulklike trench and a 5-7-5 trench requires no mass transport, only a local rebonding of atoms. However, to convert either into a flat surface, two subsurface $\mathrm{Si}$ atoms must be added (per unit trench length $d_{0}$ ). In our calculations this was done using a reservoir of bulk Si $\left(\mu_{\text {Si,bulk }}\right)$.

Structure $d$ is also energetically favorable. In this case, no mass transport is required to form a trench from a flat surface. For a trench spacing of $46 \AA\left(12 d_{0}\right)$, the energy difference is $301 \mathrm{meV}$ per unit trench length $\left(d_{0}\right)$. To demonstrate that 5-7-5 trenches are stabilized by surface strain, the average surface energy density is plotted in Fig. 4 as a function of trench spacing $n$. The diamonds are results of our $a b$ initio calculations. The line is a fit to a continuum elasticity theory that includes both surface and bulk stresses. ${ }^{2}$ Similar illustrations of this strain balance can be found for $\mathrm{Ge} / \mathrm{Si}(100),{ }^{27}$ As/Ge(111), ${ }^{10}$ and $\mathrm{Bi} / \mathrm{Si}(100)$ (Ref. 28) surfaces.

Our final calculation is for structure $e$. For a step spacing of $6.5 d_{0}$ and step height of 2 ML [Fig. 2(e)], a 5-7-5 step is $230 \mathrm{meV}$ lower in energy (per unit step length $d_{0}$ ) than a bulk-like step. No mass transport is required to create a 5-7-5

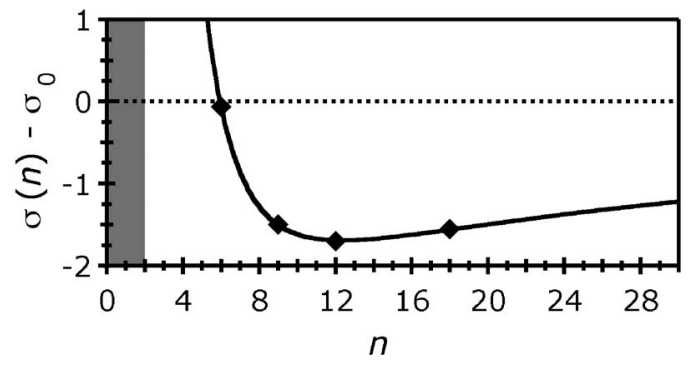

FIG. 4. Calculated average surface energy density (in $m e V / \AA^{2}$ ) as a function of spacing $n$ (in multiples of $d_{0}=3.84 \AA$ ) for an array of parallel type- $B$ 5-7-5 trenches (structure $d$ in Fig. 2). The surface energy is expressed with respect to that of a flat dimerized As $/ \operatorname{Si}(100)$ surface $\left(\sigma_{0}\right)$. Spacings less than two (shaded area) are unphysical, since a 5-7-5 structure has a finite width of $2 d_{0}$.

step from a bulklike step. A local rebonding of atoms suffices. Although even a bulklike step can distort in response to stress on adjacent terraces, ${ }^{20}$ a 5-7-5 structure can provide additional stress relief.

To bring this paper full circle, we will discuss the effect of temperature and As coverage on 5-7-5 structure formation. The role of temperature is easy to understand. Extensive rebonding is needed to create a 5-7-5 structure, ${ }^{29}$ so the activation barrier cannot be overcome at room temperature. Both our own data and published STM images ${ }^{18}$ suggest that the minimum temperature needed is roughly $600{ }^{\circ} \mathrm{C}$.

The role of As coverage is also quite clear. As the As coverage is reduced below unity, As-Si mixed dimers will form, ${ }^{30}$ reducing the surface stress ${ }^{4}$ available to stabilize 5-7-5 structures. Our $\mathrm{As}_{x}$-annealed surfaces have an As coverage of $\sim 0.7 \mathrm{ML}$ and contain few, if any, 5-7-5 structures. The abundance of 5-7-5 structures on our $\mathrm{AsH}_{3}$-annealed surfaces correlates with a very high $\mathrm{AsH}_{3}$ partial pressure (17 to 830 mtorr) and a saturation coverage of $\sim 1$ ML As.

A similar correlation between line structures and group- $\mathrm{V}$ coverage has been carefully documented for $\mathrm{PH}_{3}$ exposed $\mathrm{Si}(100) .{ }^{14}$ Line structures were observed, but only when the P coverage approached unity. At lower P coverages, the preferential formation of P-Si mixed dimers ${ }^{30,31}$ reduced the average surface stress, and no line structures were observed. ${ }^{14}$ Interestingly, the topology of $\mathrm{P} / \mathrm{Si}(100)$ line structures, which is also carefully characterized in Ref. 14 , is entirely consistent with a 5-7-5 structure.

In summary, line structures are known to form on group- $\mathrm{V}$ terminated $\mathrm{Si}$ and $\mathrm{Ge}$ surfaces in response to surface stress. It is becoming apparent that most of these line structures are based upon 5-7-5 structures. Using sample preparation conditions particularly favorable for their formation, we have observed an entire family of 5-7-5 line structures on the As/Si(100) surface. Theoretical modeling shows that they are stabilized by surface stress generated by As-As dimers.

We would like to thank Alan Kibbler for his help with these experiments. This work was supported by OER and BES, U.S. Department of Energy, under Contract No. DEAC36-99GO10337 and used resources of the National Energy Research Scientific Computing Center, which is supported under Contract No. DE-AC03-76SF00098. 
${ }^{1}$ V. A. Shchukin and D. Bimberg, Rev. Mod. Phys. 71, 1125 (1999).

${ }^{2}$ V. I. Marchenko and A. Y. Parshin, Sov. Phys. JETP 52, 129 (1980); O. L. Alerhand, D. Vanderbilt, R. D. Meade, and J. D. Joannopoulos, Phys. Rev. Lett. 61, 1973 (1988); E. Pehlke and J. Tersoff, ibid. 67, 465 (1991).

${ }^{3}$ R. D. Meade and D. Vanderbilt, Phys. Rev. Lett. 63, 1404 (1989).

${ }^{4}$ A. J. Schell-Sorokin and R. M. Tromp, Surf. Sci. 319, 110 (1994).

${ }^{5}$ J. B. Hannon, J. Tersoff, and R. M. Tromp, Science 295, 299 (2002); A. Pradhan, N.-Y. Ma, and F. Liu, Phys. Rev. B 70, 193405 (2004); J. Qin, F. Xue, Y. Wang, L. H. Bai, J. Cui, X. J. Yang, Y. L. Fan, and Z. M. Jiang, J. Cryst. Growth 278, 136 (2005).

${ }^{6}$ A. García and J. E. Northrup, Phys. Rev. B 48, 17350 (1993); J. G. Che, K. M. Zhang, and X. D. Xie, ibid. 60, 4784 (1999); Y. Tanaka and H. Hashizume, Jpn. J. Appl. Phys., Part 1 41, 256 (2002).

${ }^{7}$ R. D. Bringans, Crit. Rev. Solid State Mater. Sci. 17, 353 (1992).

${ }^{8}$ Z. T. Zhong, D. W. Wang, Y. Fan, and C. F. Li, J. Vac. Sci. Technol. B 7, 1084 (1989); F. Rochet, C. Poncey, G. Dufour, H. Roulet, W. N. Rodrigues, M. Sauvage, J. C. Boulliard, F. Sirotti, and G. Panaccione, Surf. Sci. 326, 229 (1995).

${ }^{9}$ S. B. Zhang, W. E. McMahon, J. M. Olson, and S.-H. Wei, Phys. Rev. Lett. 87, 166104 (2001).

${ }^{10}$ W. E. McMahon, I. G. Batyrev, J. M. Olson, and S. B. Zhang, Phys. Rev. Lett. 89, 076103 (2002).

${ }^{11}$ J. H. G. Owen, K. Miki, H. Koh, H. W. Yeom, and D. R. Bowler, Phys. Rev. Lett. 88, 226104 (2002).

${ }^{12}$ J.-T. Wang, H. Mizuseki, Y. Kawazoe, T. Hashizume, M. Naitoh, D.-S. Wang, and E.-G. Wang, Phys. Rev. B 67, 193307 (2003).

${ }^{13}$ L. Vitali, M. G. Ramsey, and F. P. Netzer, Phys. Rev. B 57, 15376 (1998).

${ }^{14}$ Y. Wang, X. Chen, and R. J. Hamers, Phys. Rev. B 50, 4534 (1994).

${ }^{15}$ M. D. Jackson, F. M. Leibsle, R. J. Cole, D. A. C. Gregory, D. A.
Woolf, and P. Weightman, J. Vac. Sci. Technol. B 14, 2424 (1996).

${ }^{16}$ O. Sakata, W. Yashiro, D. R. Bowler, A. Kitano, K. Sakamoto, and K. Miki, Phys. Rev. B 72, 121407(R) (2005); T. Sekiguchi, S. Yoshida, and K. M. Itoh, Phys. Rev. Lett. 95, 106101 (2005).

${ }^{17}$ H. Kroemer, J. Cryst. Growth 81, 193 (1987); L. Kipp, R. D. Bringans, D. K. Biegelsen, L.-E. Swartz, and R. F. Hicks, Phys. Rev. B 50, 5448 (1994).

${ }^{18}$ R. S. Becker, T. Klitsner, and J. S. Vickers, J. Microsc. 152, 157 (1988).

${ }^{19}$ R. D. Bringans, D. K. Biegelsen, and L.-E. Swartz, Phys. Rev. B 44, 3054 (1991).

${ }^{20}$ O. L. Alerhand, J. Wang, J. D. Joannopoulos, E. Kaxiras, and R. S. Becker, Phys. Rev. B 44, 6534 (1991).

${ }^{21}$ J. Wasserfall and W. Ranke, Surf. Sci. 315, 237 (1994); J. Wasserfall and W. Ranke, ibid. 331, 1099 (1995).

${ }^{22}$ T. Ide, Phys. Rev. B 51, 1722 (1995).

${ }^{23}$ T. Hannappel, W. E. McMahon, and J. M. Olson, J. Cryst. Growth 272, 24 (2004).

${ }^{24}$ D. J. Chadi, Phys. Rev. Lett. 59, 1691 (1987).

${ }^{25}$ X. Chen, F. Wu, Z. Zhang, and M. G. Lagally, Phys. Rev. Lett. 73, 850 (1994).

${ }^{26}$ L. Kipp, R. D. Bringans, D. K. Biegelsen, J. E. Northrup, A. Garcia, and L.-E. Swartz, Phys. Rev. B 52, 5843 (1995); D.-S. Lin, T.-S. Ku, and R.-P. Chen, ibid. 61, 2799 (2000).

${ }^{27}$ J. Tersoff, Phys. Rev. B 45, R8833 (1992).

${ }^{28}$ D. R. Bowler and J. H. G Owen, J. Phys.: Condens. Matter 14, 6761 (2002).

${ }^{29}$ J.-T. Wang, E. G. Wang, D. S. Wang, H. Mizuseki, Y. Kawazoe, M. Naitoh, and S. Nishigaki, Phys. Rev. Lett. 94, 226103 (2005).

${ }^{30}$ M. Ramamoorthy, E. L. Briggs, and J. Bernholc, Phys. Rev. Lett. 81, 1642 (1998).

${ }^{31}$ V. G. Zavodinsky and I. A. Kuyanov, Appl. Surf. Sci. 141, 193 (1999). 